\title{
Komunikasi Interprofesional Sebagai Upaya Pengembangan Kolaborasi Interprofesi Di Rumah Sakit: Systematic Review
}

\author{
Yunis Veronika Purba1, Anggorowati ${ }^{2}$ \\ ${ }^{1}$ Akper Surya Nusantara Pematangsiantar, Sumatera Utara \\ ${ }^{2}$ Fakultas Kedokteran, Universitas Diponegoro, Semarang
}

\section{Informasi Artikel}

\section{Riwayat Artikel:}

Diterima 29 Desember 2017

\section{Kata Kunci:}

Interprofesional;

Komunikasi; Kolaborasi

\section{PENDAHULUAN}

Komunikasi

Interprofessional menjadi sangat penting dalam pelayanan kesehatan saat ini, di mana dapat memperluas populasi pelayanan kesehatan khususnya dalam memberikan perawatan dalam layanan kesehatan (Craddock et al, 2006). Komunikasi interprofessional efektif adalah keterampilan penting yang dapat meningkatkan fungsi tim yang berkualitas tinggi, dalam perawatan pasien dengan melibatkan beberapa disiplin ilmu seperti dokter, perawat dan tim kesehatan lainnya (HSERC, 2010). Menurut Berridge (2010) komunikasi interprofesi merupakan faktor yang sangat berpengaruh dalam meningkatkan keselamatan pasien, karena melalui komunikasi interprofesi yang berjalan efektif, akan menghindarkan tim tenaga kesehatan dari kesalah pahaman yang dapat menyebabkan medical error. Menurut Potter dan Perry (2005) Keefektifan komunikasi interprofesional dipengaruhi oleh: 1).Persepsi yaitu suatu pandangan pribadi atas hal-hal yang telah terjadi. Persepsi terbentuk apa yang diharapkan

Corresponding author:

Yunis Veronika Purba yunispurba@gmail.com Jurnal Kepemimpinan dan Manajemen Keperawatan, Vol 1 No 1, Mei 2018 e-ISSN 2621-5047 
dan pengalaman. Perbedaan persepsi antar profesi yang berinteraksi akan menimbulkan kendala dalam komunikasi. 2).Lingkungan yang nyaman membuat seseorang cenderung dapat berkomunikasi dengan baik. Kebisingan dan kurangnya kebebasan seseorang dapat membuat kebingunan, ketegangan atau ketidaknyamanan. 3).Pengetahuan yaitu suatu wawasan akan suatu hal. Komunikasi interprofesi dapat menjadi sulit ketika lawan bicara kita memiliki tingkat pengetahuan yang berbeda. Keadaan seperti ini akan menimbulkan feedback negatif, yaitu pesan menjadi akan tidak jelas jika katakata yang digunakan tidak dikenal oleh pendengar.

Kolaborasi interprofesional adalah bekerja bersama dengan profesi kesehatan lain dalam melakukan kolaborasi, komunikasi, yang memastikan bahwa perawatan yang diberikan reliable dan berkelanjutan (IOM, 2003). Kolaborasi interprofessional dalam lingkungan kerja profesional telah diakui oleh keperawatan, dan tim kesehatan lain serta organisasi profesional kesehatan sebagai komponen penting dalam keselamatan yang mempunyai kualitas tinggi dalam memberikan pelayanan yang berpusat kepada pasien (Gul Pinar, 2015).

Salah satu kompetensi inti dalam melakukan praktek kolaborasi interprofesional adalah dengan melakukan komunikasi inter profesional dimana untuk melakukan kolaborasi dan kerja tim perawat harus mampu berkomunikasi secara efektif dengan tim kesehatan lainnya sehingga dapat mengintegrasikan perawatan yang aman dan efektif bagi pasien dan tenaga kesehatan lainnya (ANA, 2010). Komunikasi dalam kolaborasi merupakan unsur penting untuk kualitas perawatan dan keselamatan pasien. Petugas kesehatan dokter, perawat dan tim kesehatan yang lain harus bekerjasama membantu pasien untuk memecahkan masalah kesehatan yang kompleks.
Fenomena saat ini, pasien sering merasa bingung karena dua dokter (pelayan kesehatan) yang menangani penyakitnya memberikan nasehat yang berbeda atau kadang bertentangan. Lemahnya komunikasi antar petugas kesehatan dapat mempengaruhi kualitas pelayanan yang diberikan, yang pada gilirannya dapat menimbulkan kerugian pada pasien dan keluarganya. Tulisan sering digunakan oleh dokter yang merawat pasien untuk memberikan instruksi kepada petugas kesehatan lainnya misalnya dokter ruangan atau perawat/ bidan untuk melaksanakan pengobatan atau pemeriksaan penunjang, masalah yang sering timbul adalah tulisan yang sulit dibaca oleh petugas lainnya, bahkan kadang-kadang penulis sendiri pada kesempatan berikutnya tidak dapat membaca kembali tulisannya (Basuki, 2008). Kerugian yang dapat ditimbulkan adalah dokter lain tidak dapat memahami situasi pasien dengan baik sehingga tidak dapat melanjutkan perawatan dengan baik. Perawat atau bidan juga tidak dapat membaca instruksi yang seharusnya dilakukan.Tidak jarang klarifikasi melalui telepon perlu dilakukan, padahal pembicaraan melalui telepon terkadang tidak mudah dilakukan karena koneksi yang buruk atau dokter tidak mengaktifkan pesawat teleponnya. Bila tidak dapat berkomunikasi dengan pemberi instruksi, sebagian petugas menunda pekerjaan tersebut, atau menduga-duga instruksi apa yang harus dilaksanakan. Instruksi yang kurang jelas dan tidak diklarifikasi dapat berakibat fatal bagi pasien. Bayangkan apabila komunikasi antar petugas kesehatan tidak berjalan dengan baik. Misalnya dokter yang menulis resep untuk pasien, akan tetapi apoteker tidak dapat membaca resepnya dengan baik. Hal ini dapat menimbulkan adanya kesalahan pemberian obat atau dosis yang tidak sesuai dengan kebutuhan pasien dan kemungkinan dapat berakibat fatal (Sudarma, 2008) ' 
Komunikasi adalah proses interpersonal yang melibatkan perubahan verbal dan nonverbal dari informasi dan ide. Sedangkan komunikasi terapeutik adalah proses dimana perawat yang menggunakan pendekatan terencana mempelajari klien. proses memfokuskan pada klien namun direncanakan dan dipimpin oleh seorang profesional. (Potter \& Perry, 2009).

Komunikasi Interprofesional dalam kolaborasi interprofesi memerlukan cara atau strategi agar komunikasi berjalan dengan efektif. Beberapa cara agar terjalin komunikasi yang efektif yaitu berkomunikasi dengan detail, cepat, akurat, serta disertai dengan bukti. Komunikasi secara detail seperti melakukan pertukaran informasi dengan lebih terperinci.
Sistematic review ini bertujuan untuk menegetahui apakah komunikasi interprofesional dapat mengembangkan upaya kolaborasi interprofesi di rumah sakit

\section{METODE}

Metode berupa sistematik review dengan batasan kriteria inklusi artikel yang dicari yaitu: Partisipan dalam artikel adalah tenaga kesehatan, intervensi yang di gunakan adalah komunikasi interprofesional, tipe outcome yang di ukur yaitu kemampuan tenaga kesehatan/ tim interprofesional dalam melakukan kolaborasi. Kriteria eklusi non internasional. Pencarian di batasi pada tahun 2009-2014.

\section{Tabel 1. Proses Pencarian Literatur}

\begin{tabular}{lccc}
\multicolumn{1}{c}{$\begin{array}{c}\text { Mesin } \\
\text { Pencari }\end{array}$} & $\begin{array}{c}\text { Google } \\
\text { scholar }\end{array}$ & $\begin{array}{c}\text { Science } \\
\text { Direct }\end{array}$ & Proquest \\
\hline Hasil Penelusuran & 680 & 6 & 18 \\
Fulltext, pdf, 2009-2014 & 105 & 6 & 18 \\
Judul yang sama & 20 & 1 & 2 \\
Eligible Sesuai Kriteri Inklusi dan & 3 & - & - \\
Eklusi & & & \\
RESULT & & 3 & \\
\hline
\end{tabular}

\section{Hasil}

Setelah dilakukan pencarian literatur sesuai batasan karakteristik terdapat 3 artikel yang di pilih. Masing-masing artikel menghasilkan tema yang berbeda.

\section{Tabel 2. Hasil Penelusuran Literatur}

\begin{tabular}{lll}
\hline Author & Metode & Outcome \\
\hline $\begin{array}{l}\text { Esther Suter,et } \\
\text { al. (2009) }\end{array}$ & Studi kualitatif & $\begin{array}{l}\text { Memahami dan menghargai peran dan tanggungjawab profesional dan } \\
\text { berkomunikasi secara efektif muncul sebagai dua kompetensi inti yang } \\
\text { dirasakan untuk praktek kolaboratif berpusat pada pasien. Untuk kedua } \\
\text { kompetensi ada bukti link ke pasien dan menghasilkan hasil positif. }\end{array}$ \\
\hline $\begin{array}{l}\text { Rice Kathleen, } \\
\text { et al (2010) }\end{array}$ & Kualitatif & $\begin{array}{l}\text { Dalam pelayanan kesehatan dimana tatap muka, komunikasi } \\
\text { interprofessional spontan tidak bermusuhan dan impersonal (tidak } \\
\text { bersifat pribadi/adil ), memiliki manfaat yang dirasakan dari peningkatan } \\
\end{array}$ \\
& $\begin{array}{l}\text { yang cukup untuk menerapkan perubahan komunikasi sederhana dan } \\
\text { berpotensi menguntungkan, dalam menghadapi kebiasaan, dan tidak } \\
\text { adanya dokter yang senior dan dukungan manajemen. }\end{array}$ \\
\hline Vasiliki & $\begin{array}{l}\text { Serawat dan dokter harus mengakui pentingnya komunikasi yang efektif } \\
\text { dan mereka harus mengembangkan dan menerapkan intervensi kerja tim }\end{array}$ \\
\hline
\end{tabular}


Matziou,et al test dan uji chi interprofessional untuk meningkat-kan kerjasama.

(2014)

square

\section{PEMBAHASAN}

Pengembangan

kolaborasi

Interprofesi dapat dilakukan dengan

melakukan komunikasi interprofe-sional dimana untuk melakukan kolaborasi dan kerja tim perawat harus mampu berkomunikasi secara efektif dengan tim kesehatan lainnya sehingga dapat mengintegrasikan perawatan yang aman dan efektif bagi pasien dan tenaga kesehatan lainnya (ANA, 2010). Contoh komunikasi interprofesional yang di gunakan adalah SBAR (Situation Background Assessment Recommendation). SBAR merupakan tehnik dalam mengkomunikasikan informasi yang penting yang membutuhkan perhatian dan tindakan dengan segera sehingga keselamatan pasien dapat terjamin dan terlindungi. Kolaborasi Inter-profesi yang dilakukan dokter, perawat dan tenaga kesehatan lainnya semuanya berorientasi kepada pasien. Dalam situasi apapun, praktik kolaborasi yang baik harus dapat menyesuaikan diri secara adekuat pada setiap lingkungan yang dihadapi sehingga anggota kelompok dapat mengenal masalah yang dihadapi pasien, sampai terbentuknya diskusi dan pengambilan keputusan. (Siegler \& Whitney, 1994).

Kerja sama interprofesi terjadi ketika berbagai profesi tenaga kesehatan dari latar belakang profesi yang berbeda bekerjasama dengan pasien, keluarga, pengasuh, dan masyarakat untuk memberikan kualitas pelayanan yang terbaik (WHO, 2010).

Masing-masing profesi memiliki kompetensi profesional yang berbeda sehingga ketika digabungkan dapat menjadi kekuatan untuk mencapai tujuan yang diharapkan, banyaknya faktor yang berpengaruh seperti kerjasama/ sering tatap muka, sikap saling menerima, berbagi tanggung jawab, komunikasi efektif dan spontan sangat menentukan bagaimana suatu tim berfungsi. Oleh karena itu tim kolaborasi hendaknya memiliki komunikasi yang efektif, bertanggung jawab dan saling menghargai dan membutuhkan (rasa adil) antar sesama anggota tim (Berger, 1999).

Menurut Sargeant (2008) Tujuan Kolaborasi Tim Kesehatan adalah: 1.Untuk meningkatkan kualitas dalam memberikan pelayanan kesehatan terhadap pasien,

2.Untuk meminimalisir masalah masalah yang berkenaan dengan kebutuhan kesehatan pasien, 3.Untuk meningkatkan pemahaman kontribusi setiap anggota tim kesehatan sehingga masing-masing anggota tim kesehatan dapat berkontribusi sesuai dengan profesi masing-masing, 4.Menumbuhkan komunikasi, kolegalitas, menghargai dan memahami orang lain khususnya antar anggota tim kesehatan.

Perawat menjalankan peran yang membutuhkan interaksi dengan berbagai anggota tim pelayanan kesehatan. Unsur yang membentuk hubungan perawat klien juga dapat diterapkan dalam hubungan sejawat, yang berfokus pada pembentukan lingkungan kerja yang sehat dan mencapai tujuan tatanan klinis. Komunikasi ini berfokus pada pembentukan tim, fasilitasi proses kelompok, kolaborasi, konsultasi, delegasi, supervisi, kepemimpinan, dan manajemen. Dibutuhkan banyak keterampilan komunikasi, termasuk berbicara dalam presentasi, persuasi, pemecahan masalah kelompok, pemberian tinjauan performa, dan penulisan laporan. Didalam lingkungan kerja, perawat dan tim kesehatan membutuhkan interaksi sosial dan terapeutik untuk membangun kepercayaan dan meperkuat hubungan. Semua orang memilki kebutuhan interpribadi akan penerimaan, keterlibatan, identitas, privasi, kekuatan dan kontrol, serta perhatian. Perawat membutuhkan persahabatan, dukungan, bimbingan, dan 
dorongan dari pihak lain untuk mengatasi tekanan akibat stress pekerjaan dan harus dapat menerapkan komunikasi yang baik dengan klien, sejawat dan rekan kerja. (Potter \& Perry, 2009).

Komitmen untuk kolaborasi dalam hubungan kerja dengan para profesional lain membantu mempertahankan kualitas tinggi dari perawatan klien. Keberhasilan kelompok bergantung pada hubungan baik diantara tim, terutama pemimpin tim dengan anggota tim yang lain. Untuk mendorong terjadinya komunikasi, pemimpin tim harus selalu mengamati prinsip komunikasi menurut WHO, 1999 : 1. Seluruh anggota tim harus bebas mengemukakan dan menjelaskan pandangan mereka dan harus didorong untuk bertindak seperti itu, 2. Sebuah pesan atau komunikasi, baik lisan maupun tertulis harus dinyatakan dengan jelas dan dalam bahasa atau ungkapan yang dapat dimengerti, 3. Komunikasi mempunyai dua unsur yaitu mengirim dan menerima, bila pesan yang dikirim tidak diterima komunikasi tidak berjalan. Dengan demikian pemimpin tim harus selalu meggunakan suatu cara untuk memeriksa apakah efek yang diharapkan terjadi, 4. Perselisihan atau pertentangan adalah normal dalam hubungan antar manusia, hal ini sudah diatur sedemikian sehingga dapat mencapai hasil yang konstruktif.

Kolaborasi adalah hubungan timbal balik dimana pemberi pelayanan memegang tanggung jawab paling besar untuk perawatan pasien dalam kerangka kerja bidang respektif mereka. Praktik keperawatan kolaboratif menekankan

tanggung jawab bersama dalam manajemen perawatan pasien, dengan proses pembuatan keputusan bilateral didasarkan pada masing-masing pendidikan dan kemampuan praktisi. (Siegler \& Whitney, 2000).

\section{Defenisi kolaborasi dapat} disimpulkan yaitu hubungan kerja sama antara perawat dan dokter dalam memberikan pelayanan kesehatan kepada klien yang didasarkan pada pendidikan dan kemampuan praktisi yang memiliki tanggung jawab dalam pelayanan kesehatan khususnya pelayanan keperawatan. kolaborasi sebagai hubungan kemitraan yang bergantung satu sama lain dan memerlukan perawat, dokter dengan profesi lain untuk melengkapi satu sama lain ahli-ahli berperan secara Hirarki.

Komunikasi yang efektif dalam kolaborasi penting untuk memecahkan masalah komlpeks. Komuniksai efektif dapat terjadi hanya apabila kelompok yang terlibat berkomitmen untuk saling memahami peran professionalnya dan saling menghargai sebagai individu. Selain itu, mereka harus sensitif terhadap perbedaan antara gaya komunikasi.

Salah satu yang dihadapi para professional adalah memberi dan menerima umpan balik pada saat yang tepat, relevan, dan membantu untuk dan dari satu sama lain, dan klien mereka. Umpan balik dapat dipengaruhi oleh persepsi, ruang personal, peran, hubungan, harga diri, percaya diri, keyakinan, emosi, lingkungan, dan waktu dari masing-masing orang. Umpan balik yang positif dicirikan dengan gaya komunikasi yang hangat, perhatian, dan penuh penghargaan. Tinjauan mengenai keterampilan komunikasi dasar, dan kesempatan untuk praktik mendengarkan serta memberi dan menerima umpan balik dapatmeningkatkan kemampuan professional, agar dapat melakukan komunikasi dengan efektif. Memberi dan menerima umpan balik, membantu individu mendapatkan kesadaran sendiri, membantu tim kolaboratif untuk membangun pemahaman dan hubungan kerja yang efektif.

Setiap petugas kesehatan seyogyanya menerapkan keterampilan komunikasi interpersonalnya bila berhadapan dengan sesama petugas kesehatan. Komunikasi tertulis hendaknya ditunjang dengan penulisan yang jelas, dan bila perlu didukung oleh komunikasi verbal dan nonverbal yang sesuai. Menciptakan situasi yang nyaman dalam lingkungan kerja perlu dilakukan dan sebenarnya sangat mudah dilakukan bila semua petugas kesehatan 
menyadari bahwa hasilnya akan sangat bermanfaat bagi pasien yang telah memberikan amanah kepada mereka, bukan kepada orang lain, untuk merawat.

Model komunikasi interprofesional dapat dijadikan suatu media pembelajaran bagi tim kesehatan untuk belajar dan melatih kemampuan dalam melakukan kolaborasi dengan profesi lain.

Keterbatasan sistematik review ini adalah hanya 3 artikel saja yang di review. Selain itu reviewer hanya melakukan review pada artikel yang menggunakan bahasa inggris saja.

\section{KESIMPULAN}

Komunikasi interprofesional secara efektif dapat di gunakan sebagai upaya pengembangan kolaborasi interprofesi di rumah sakit, dengan adanya komunikasi interprofesional yang efektif maka perawat, dokter, maupun tim kesehatan lainnya dapat saling menghargai dan dapat memiliki visi dan misi yang sama dalam memberikan layanan kepada klien guna meningkatkan mutu pelayanan dan kepuasan bagi klien sendiri.

\section{DAFTAR PUSTAKA}

Basuki, endang. 2008. Komunikasi antar petugas kesehatan dalam majalah kedokteran Indonesia. Volume 58 no.9.

Berridge, E-Jmackintosh, N.J \& freeeth, DS., (2010) Supporting patient safety: Examinng communication within delivery suite teams through colaborasting approaaches to research observation. Midwifwery, 26 (5), pp512-9. Availableat: http://lingkinghub.elsevier.com/retrieve/pii/ S0925753511003523

Berger, J. Karen and Williams. 1999. Fundamental of Nursing; Collaborating for Optimal Health, Second Editions. Apleton and Lange. Prenticehall. USA

Craddock, D., C. O'Halloran, A. Borthwick and K. McPherson (2006), 'Interprofessional education in health and social care: fashion or informed practice?' Learning in Health and Social Care,5 (4), 220-42
Esther Suter, 2009. Role under-standing and effective com-munication as core competencies for collaborative prac-tice. Diterbitkan online: 6 Juli 2009

Gul

Pinar.(2015).Simulation-Enhan-ced Interprofessional Educa-tion in Health Care. Creative Education, 2015, 6, 1852-1859. Published Online October 2015 in SciRes. http://www.scirp.org/journal/ce

Potter, P.A, Perry, A.G. Buku Ajar Fundamental Keperawatan: Konsep, Proses dan Praktik. Edisi 4. Volume 2. Alih Bahasa: Renata Komalasari, dkk. Jakarta: EGC. 2005

Potter \& Perry. (2009).Fundamental keperawatan (7 th ed.).(vols 2.). $\mathrm{dr}$ Adrina \&marina, penerjemah). Jakarta : Salemba Medika.

Rice Kathleen, 2010. An intervention to improve interprofessional collaboration and communications: a comparative quali-tative study. July 2010

Sargeant,Joan et.all. 2008. Effective interprofessional team. Inter-science, Journal of continuing education in the health professions

Sudarma, M. 2008. Sosiologi untuk kesehatan. Jakarta: Salemba Medika

Siegler, Eugenia L, MD and Whitney Fay W, PhD, RN., FAAN (1994), alih bahasa Indraty

Secillia, 2000. Kolaborasi Perawat-Dokter ; Perawatan Orang Dewasa dan Lansia, EGC. Jakarta

Vasiliki Matziou, 2014. Physician and nursing perceptions concerning interprofessional communication and collabo-ration. Published online: 9 Oct 2014

WHO (1999).Manajemen Pelayanan Kesehatan Primer.(2 th ed). (dr.Popy Kumalasari, Penerjemah).Jakarta : EGC

World Health Organization (2010). summary of progress towards the health-related Millennium Development Goals and targets 